\title{
EGFR NP_005219.2:p.V765_M766insMAS
}

National Cancer Institute

\section{Source}

National Cancer Institute. EGFR NP 005219.2:p.V765 M766insMAS. NCI Thesaurus.

Code C98605.

An insertion of the amino acid sequence methionine-alanine-serine between the valine at position 765 and the methionine at position 766 of the epidermal growth factor receptor protein. 